\title{
STUDY OF IODINE OXIDE PARTICLES AT THE AIR/SEA INTERFACE IN THE PRESENCE OF SURFACTANTS AND HUMIC ACID
}

\author{
Salah Eddine Sbai ${ }^{1,2, *}$, Bentayeb Farida ${ }^{1}$
}

https://doi.org/10.23939/chcht13.03.341

\begin{abstract}
In the present study, the formation procedure of iodine oxide particle (IOP) has been investigated in the presence of surfactants (nonanoic and stearic acids NASA) and humic acid (HA). It was established that iodine oxide which was mixed with the organic compounds (HA, NA and SA), and then irradiated with a xenon lamp leads to the formation of IOP. The evolution of formed particles number was followed by a scanning mobility particle sizer. Results obtained show that the number of particles decreases strongly in the presence of HA, NA and SA, this behavior is explained by the formation of organoiodine compounds.
\end{abstract}

Keywords: photochemistry, surfactants, iodine, particle, organoiodine.

\section{Introduction}

Photochemistry at the air/sea interface of halogens affects the chemical composition of the troposphere. Atmospheric chemistry of halogens is dominated by reactions between gas and aqueous phases species on ocean surfaces and marine aerosols [1]. It influences the oxidation capacity of the atmosphere by removing the great variety of organic and inorganic species, which are emitted by natural and anthropogenic sources, this occurs by the catalytic destruction of ozone and reactions with the important radical species (in particular the hydroxyl $\mathrm{OH})$ which control the oxidation chemistry $[2,3]$. The reactivity of iodine in the atmosphere and at sea level leads to the production of nanoparticles of iodine oxide (IOP). The production process of IOP involves the recombination reactions of the radicals $\mathrm{IO}$ and $\mathrm{OIO}$ to form oxides which then spontaneously condense forming particles $[4,5]$. In the presence of moisture, these particles develop into clouds condensation nuclei $(\mathrm{CCN})$, which

\footnotetext{
${ }^{1}$ Department of physics, Mohammed V University of Rabat,

4, Ave. Ibn Battouta B.P. 1014 RP, Rabat, Morocco

${ }^{2}$ University Lyon, University Claude Bernard Lyon 1, CNRS, IRCELYON,

2, Albert Einstein Ave., 69100 Villeurbanne, France

* salaheddinechimie@gmail.com.

(c) Sbai S., Farida B., 2019
}

would have an impact on the radiative balance of the atmosphere and therefore on the climate [6-11].

Some studies $[12,13]$ indicate the presence of a significant fraction of iodine soluble in marine aerosol in an organic form. The reaction mechanism between the dissolved organic matter (DOM) and the species aqueous HIO (hypoidic acid), which would recycle $\mathrm{I}^{-}$in aerosols and also increase the release of $\mathrm{I}_{2}$, in the gaseous phase and at the air/sea interface has already been studied [14]. This mechanism is highly dependent on pH. Humic acid (HA) is a diverse group of multifunctional organic compounds that are soluble in water at $\mathrm{pH}$ values above 4 . It contains chromophores that participate in photosensitized chemical reactions in the presence of organic surfactants such as nonanouique acid (NA). The adsorption of the soluble reagents, such as $\mathrm{O}_{3}$ and $\mathrm{H}_{2} \mathrm{O}_{2}$, of the gas phase on the aerosol surfaces will potentially lead to the oxidation of $\mathrm{I}^{-}$ directly to the aerosol of the seawater [15]. The release of these species into the atmosphere allows the recycling of iode to iodine $\mathrm{I}^{-}$and iodine monoxide IO, which reacts actively with ozone and leads to the formation of iodine oxide particles (IOP) $[16,17]$. The iodine oxide species $\mathrm{IO}_{3}{ }^{-}$ is converted by a photochemical reaction with HA to the aqueous ionic form $(\mathrm{I})$; this reaction is also showing the binding of the iodinated species to the humic acid, which influences the formation of marine particles. The spectroscopic analysis of iodate reactions with a number of compounds substituted with functional groups identified with structures of HA, were used to identify the chemical pathways and major species involved in the formation of non-volatile organic species containing iodine [15]. The reaction mechanism is likely to occur in the fixation of iodate on the HA and was, first of all, the absorption of visible light by the organic chromophores of HA, which leads to the generation of the solvated electrons, which are then captured by the iodate ion $\mathrm{IO}_{3}^{-}$, which is considered as the species of the most active iodine in the formation of particles in the atmosphere. It is reduced to HOI which will produce the molecular iodine $I_{2}$ which reduces the number of IOP [15]. Iodate is accumulated in the marine aerosol by the adsorption of the species $\mathrm{I}_{2} \mathrm{O}_{3}, \mathrm{I}_{2} \mathrm{O}_{4}$ and $\mathrm{I}_{2} \mathrm{O}_{5}$ of the gas phase [18]. Most of the active chemistry of iodine in the gas phase takes place in the first 30 meters of the boundary 
layer [19]. Natural compounds containing bromine and iodine significantly reduce regional and global tropospheric ozone levels [20, 21]. These halogenated gases reduce the effects of global warming of ozone and hydrocarbons such as methane in the troposphere. Organic iodine compounds have been considered as the main source of oceanic iodine emissions. The reaction of ozone with iodide on the sea surface could represent about $75 \%$ of the rates of iodine oxide observed in the tropical Atlantic Ocean [22].

According to several studies, the reaction of molecular iodine $\mathrm{I}_{2}$ with DOM and the hypoiodic acid (HOI) with $\mathrm{Cl}^{-}$and $\mathrm{Br}$ - leads to the decrease of the particle concentration in the atmosphere. Organic surfactants cause a decrease in $\mathrm{I}_{2}$ gas emissions and reduce gas-air transfer rates which directly influence the number of particles emitted [23, 24]. Dissolved organic matter such as humic acid present on the surface of the sea [27], can be highly concentrated in the marine microlayer [26-28]. The presence of these complex and potentially photoactive compounds affects the mechanism of marine aerosols formation. Some researches [29-32] have studied organic enrichment in the marine microlayer in different regions of the ocean (subtropical, temperate, polar). They observed a much larger coverage than before and showed that the part of the oceans can be assumed to be completely covered by an organic layer of thickness $100 \mu \mathrm{m}$ [33], especially $\mathrm{C}_{9}$ carboxylic acids like NA during the autumn. The presence of these compounds affects the production mechanism of IOP. For this we decided to study the formation of IOP in the presence of DOM in the form of HA which is also considered as a photosensitizer, and in the presence of organic surfactants (NA, SA) which are ubiquitous in the marine environment. A very recent study [34] shows that photochemical halogenation of DOM may represent an important abiotic source of natural organoiodine compounds (OICs) in surface waters. The OICs were mainly in the region rich in alicyclic carboxylic molecules consisting of esterified phenolic compounds. The OICs could potentially have adverse health effects due to their relatively high cytotoxicity and genotoxicity [37]. Currently about 200 of natural OICs have been identified [38], most of them are produced in the marine environment.

The objective of this study is to highlight the effect of photosensitized organic films photochemistry at the air/sea interface on iodine oxide particles IOP, using fatty acids ubiquitous in the marine environment (NA, SA) as surfactants and HA as DOM and photosensitizer.

\section{Experimental}

Freshly prepared aqueous solutions of NaI (SigmaAldrich, purity $\geq 99.5 \%)$ in ultrapure water $(18 \mathrm{M} \Omega \cdot \mathrm{cm})$ were used. HA solutions were prepared using a commercially available untreated form (Fluka). A small amount of solid was stirred in ultrapure water for $2-3 \mathrm{~h}$, and then any undissolved material was filtered. The surfactant monolayer was prepared by adding a known concentration of either nonanoic acid or stearic acid to the solution by a micropipette. The $\mathrm{pH}$ value of the solution was raised to about 8 using sodium hydroxide solution. Humic acid was fully soluble under the slightly acidic conditions used in this study $(\mathrm{pH}>4)$. We can assume that HA was evenly distributed in the reactor. The chemistry products used were: nonanoic acid (Alfa Aesar, $97 \%$ ) and humic acid (Fluka, technical grade, 97\%). Oxygen used for the generation of ozone was purchased from Linde $(99.9991 \%)$.

Solutions of iodate and HA were mixed and placed in the reactors (volume of $132 \mathrm{~cm}^{3}$ ). The irradiation was carried out by a $1000 \mathrm{~W}$ xenon arc lamp (Oriel "Solar Simulator" without ozone). The lamp beam was optically filtered using a water filter to eliminate IR wavelengths and prevent heating of the solution. A mass of solar air filters the spectrum of the lamp in order to replicate the solar spectrum in the near UV-visible and a cut-off filter to eliminate one of the small outputs of the lamp at $\lambda<310 \mathrm{~nm}$. The solution was continuously exposed to the filtered lamp beam during all experiments at room temperature $(293 \pm 1 \mathrm{~K})$.

A flow of a carrier gas of $100 \mathrm{ml} / \mathrm{min}$ at atmospheric pressure was used during the experiments, which gave a residence time equal to $100 \mathrm{~s}$. The reactor was washed twice with acetone and ethanol to remove all traces of organic compounds, thus avoiding any possible contamination.

Ozone was added directly to the reactor to facilitate oxidation of I to IO and formation of iodinated oxides. The production of iodine oxide particles (IOP) was initiated by the nucleation of these oxides in the gas phase, the size distribution of these nanoparticles was then measured using a scanning mobility particle sizer (SMPS) composed of a differential mobility analyzer (DMA, model 3081) coupled with a condensation particle counter (CPC, model 3776). Fig. 1 shows the diagram of our manipulation.

\section{Results and Discussion}

The photochemistry of surfactants (as NA) in the presence of a photosensitizer (HA) leads to the formation of unsaturated volatile organic compounds (VOCs) [39, $40]$ and the chemical transformation of NA, which leads to the formation of double bonds (i.e, removal of water). It also shows that the reaction is produced at the level of the surface microlayer (SML), which is defined as the tens to 
hundreds of microns of the surface of the ocean from the surface of the Earth [41], it is enriched by DOM substances including HA that absorbs UV. According to several studies [40-42] photosensitized reactions initiated by a substance capable of absorbing the light (HA) and of transferring the energy towards the desired reagents (for example NA) at the air/sea interface, constitute a predominant process for the formation of $\mathrm{VOC}$ in the marine environment, that can react with ozone in the atmosphere and at the air/sea interface and produce secondary organic aerosols (SOA). However in the marine environment the presence of marine salts such as iodine,
(NaI, $1 \mu \mathrm{M}$ ), which is considered as the key species that leads to the production of marine aerosols, interactions between iodine and fatty acids (HA, NA and SA) may affect the formation of marine aerosols. For this we studied the formation of IOPs in the presence of the humic acid (HA) as a photosensilizer and the nonanoic acid (NA) and the stearic acid (SA) as surfactants, we have noticed that the concentration of IOP iodine particles always decreases in the presence of these organic acids, moreover our experiments of these acids in the absence of iodine showed that the number of SOA particles does not exceed $200 \# / \mathrm{cc}$ (particles/cm ${ }^{3}$ ) (Fig. 2).

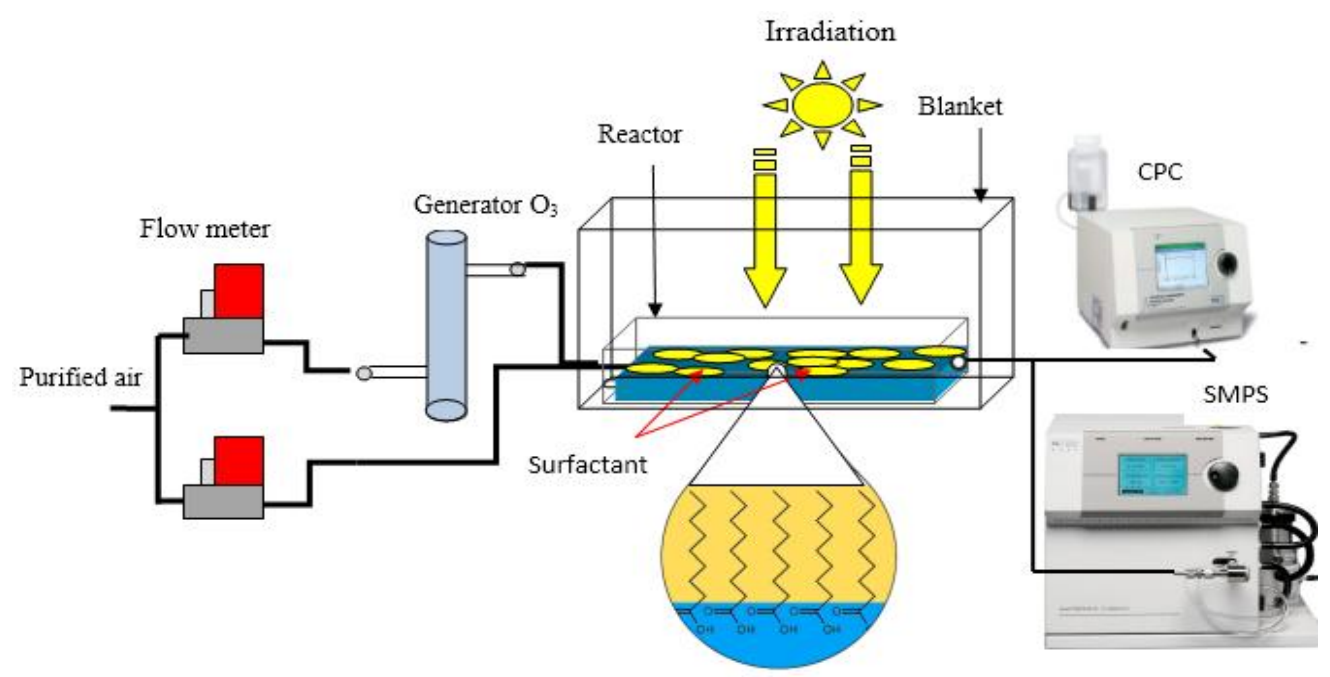

Fig. 1. Scheme of the multiphase atmospheric simulation reactor used for the investigation of photochemical processes at the air-sea interface

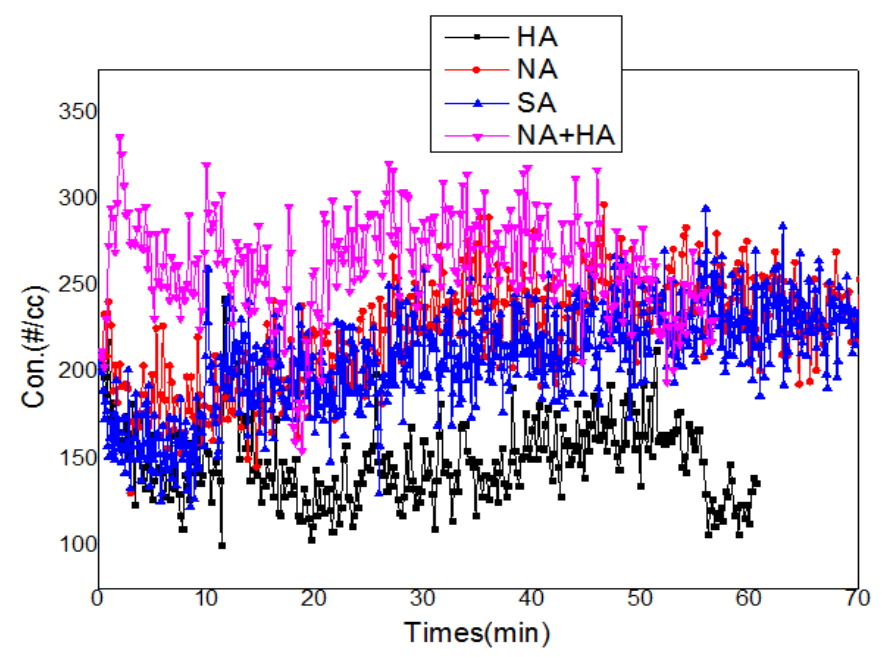

Fig. 2. Variation of the particles secondary organic aerosol (SOA) of $\mathrm{HA}, \mathrm{SA}, \mathrm{NA}$ and (HA+NA), in the presence of $20 \mathrm{ppb}$ of ozone and under the effect of irradiation

The concentrations of SOA after the irradiation period were found in the range of $120-320 \# / c c$, they remain stable indicating that the presence of SOA as a background level will not affect our observations on the concentration of IOP. 
Photolysis of NA in the presence of HA leads to the formation of VOCs such as saturated aldehydes $\left(\mathrm{C}_{7}-\mathrm{C}_{9}\right)$, unsaturated aldehydes $\left(\mathrm{C}_{6}-\mathrm{C}_{9}\right)$, alkanes $\left(\mathrm{C}_{7}-\mathrm{C}_{9}\right)$, alkenes $\left(\mathrm{C}_{5}-\mathrm{C}_{9}\right)$, and dienes $\left(\mathrm{C}_{6}-\mathrm{C}_{9}\right)$. The reaction of these VOCs with ozone and $\mathrm{OH}$ radicals leads to the formation of SOAs. The mechanisms leading to the gas phase products observed in the presence of HA and NA have been described in detail by several studies [33]. They lead to the formation of saturated acids, unsaturated and saturated aldehydes which are very soluble in water. According to Henry's law, the solubility of nonoxygenated compounds is very low compared to that of oxygenates. A recent study was carried out in a simulation chamber in the presence of high concentrations of ozone (250-850 ppb), compared to those in the atmosphere (20-50 ppb) [33]. These fairly high ozone levels were used to compensate the low light intensity of UV lamps compared to solar radiation and the possible loss of reactive VOC on the chamber wall. However, the use of a high concentration of ozone can modify the reaction mechanism and leads to the ozonolysis and decarboxylation of organic acids by $\mathrm{OH} \bullet$ radicals, producing a high number of SOA which is not our objective.

These problems make the work in the simulation chamber difficult under atmospheric conditions, and for this we used this reactor. The advantage of this reactor compared to the simulation chamber is that it is widely used for studying the aging phenomenon at the air/sea interface, has very short residence time $(100 \mathrm{~s})$ and background that does not exceed 20 \#/cc.

The concentration of SOA found by photochemistry of NA in the absence of HA was almost similar to that found with the system NA-HA. The results obtained show that the photochemical processes of the NA-HA system are not a significant source of particles under these experimental conditions. When comparing these results with those obtained in the simulation chamber which shows the production of a high number of SOA particles $(3060 \# / c c)$ [33], we have checked whether they are particles that come from the reaction of VOCs produced by the system photochemistry (NA+HA) or by reactions of these with ozone and $\mathrm{OH}$ radicals. For this purpose we conducted a series of experiments with these organic compounds (NA, SA and HA) under the same conditions as those carried out in the simulation chamber [33]. For all the experiments the formation of particles started only after irradiation and addition of ozone (Fig. 3). The results obtained using NA (1 mM) alone with $800 \mathrm{ppb}$ of ozone show that the number of IOP increases strongly after the irradiation from $10^{2}$ to $810^{3} \mathrm{H} / \mathrm{cc}$, however the photochemistry of NA photosensitized by HA produces almost $10^{6} \# / \mathrm{cc}$. The difference between these results and those obtained by the surfactant alone is due to the reactions of VOCs produced by the system (NA-HA) with $\mathrm{OH}$ radicals and ozone.

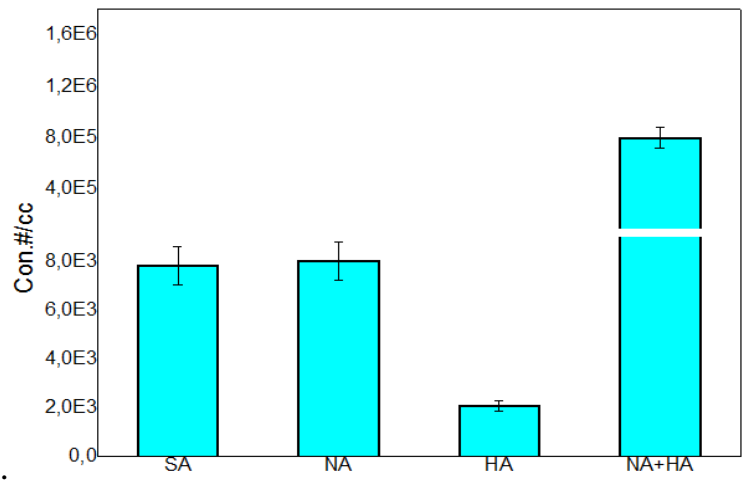

Fig. 3. Evolution of SOA concentration of in the presence of $800 \mathrm{ppb}$ of ozone

It is well established that the $\mathrm{OH}$ radicals in an aqueous phase are generated by the absorption of light from humic substances but especially by the ozone photolysis [28-30]. Particle formation was only observed after irradiation and addition of ozone (Fig. 3). The results obtained using NA alone $(1 \mathrm{mM})$ with $800 \mathrm{ppb}$ of ozone shows that the number of IOPs after the irradiation strongly increases from $10^{2}$ to $810^{3} \mathrm{~A} / \mathrm{cc} ; \quad \mathrm{NA}$ photosensitized by HA produced nearly $10^{6} \# / \mathrm{cc}$. This difference is due to the reactions of the VOCs produced by the system (NA-HA) and $\mathrm{OH}$ radicals. NA is an effective sensor of $\mathrm{OH}$ radicals, and acting as an inhibitor of any secondary reaction of $\mathrm{OH}$. These results show that the photochemistry of these organic acids under atmospheric conditions does not lead to the production of particles.

To study the effect of surfactants (NA, $1 \mathrm{mM}$ ) and organic matter (HA, $10 \mathrm{mg} / \mathrm{l}$ ) on the mechanism of IOP formation we conducted a series of experiments with iodine (NaI, $1 \mathrm{mM})$ in the absence and in the presence of organic acids (NA, SA, HA) separated and mixed under atmospheric conditions $\left(20 \mathrm{ppb} \mathrm{O}_{3}, 295 \mathrm{~K}, 1 \mathrm{~atm}\right)$, we noticed that the concentration of IOP decreased in the presence of surfactants (NA, SA) and the photosensitizer (HA). This shows that the concentration of the surface film, as well as the concentration of DOM in the volume, affect the formation of IOP (Fig. 4).

The concentration of IOP (iodine alone) decreased from $1.2 \cdot 10^{6}$ to $2 \cdot 10^{3} \# / \mathrm{cc}$ in the presence of organic matter (HA). This decrease is explained by the formation of organoiodines compounds $\left(\mathrm{OIC}_{S}\right)$ via halogenation reactions of iodine with humic acid and involves the important iodine gases such as $\mathrm{CH}_{3} \mathrm{I}, \mathrm{CH}_{2} \mathrm{I}_{2}, \mathrm{CHClI}_{2}$ and $\mathrm{CHI}_{3}$, which damage the atmospheric ozone layer. These gases are produced by abiotic mechanisms in natural environments $[43,44]$. Organoiodines compounds can also come from biotic pathways, in particular by nonspecific halogenation of dissolved organic matter, considering the covalent binding capacity of iodine to DOM [45]. 
The halogenation of DOM by photochemically generated reactive halogen species (RHS) contribute significantly to the formation of a much wider variety of OIC. Their molar masses vary between 178.916 $\left(\mathrm{C}_{7} \mathrm{H}_{4} \mathrm{IO}_{4}\right)$ and $713.1933\left(\mathrm{C}_{30} \mathrm{H}_{51} \mathrm{I}_{2} \mathrm{O}_{3}\right)$, their structures depend on the type of reaction involved and the type of irradiation, as well as the water used (artificial fresh water or seawater) [34].

The mechanisms of the main reactions involved are as follows: firstly, the absorption of sunlight by DOM leads to the generation of reactive oxygen species (ROS) comprising the hydroxyl radical $(\mathrm{OH})$, hydrogen peroxide $\left(\mathrm{H}_{2} \mathrm{O}_{2}\right)$ and DOM triplet state $\left(3 \mathrm{DOM}^{*}\right)$ [46]. Then, iodide or $\mathrm{IO}_{3}{ }^{-}$were oxidized/reduced by DOM induced ROS to form reactive halogen species (RHS) [47, 48]. After that, RHS would react with DOM to form OCIs by addition to the unsaturated $\mathrm{C}=\mathrm{C}$ bond, and recombination with carbon radicals and/or electrophilic substitution [49, 50]. The compounds formed are grouped into three categories according to the type of reaction: (i) substitution reaction (SR) between the reactive halogen species (RHS) and the organic matter (DOM); (ii) addition reaction (AR) between RHS and DOM; (iii) SR or AR accompanied by other reactions such as photooxidation (SAOR).

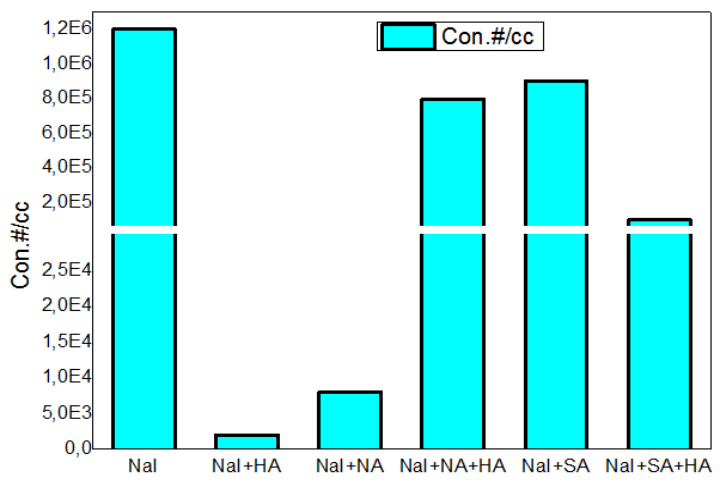

Fig. 4. Evolution of the IOP concentration in the presence and absence of surfactants (NA+SA) and the photososibilser HA

Effect of organic surfactants (NA, SA) on the formation of IOPs in the absence of DOM.

In the presence of NA as a surfactant, the number of IOP particles decreases from $1.2 \cdot 10^{6}$ to $8 \cdot 10^{3} \mathrm{\#} / \mathrm{cc}$ even if the latter always remains on the surface. Such behavior is explained by the reaction of the VOCs produced by the photochemistry of surfactant NA with the iodinated species at the air/water interface and gas phase, whereas SA showed no effect. To explain these results, we have studied photochemistry of SA by TOF-PTR-MS. The results obtained show that there is no formation of VOCs, therefore the presence of SA did not affect the formation of IOP in contrast to NA which produces VOCs.
Effect of NA and SA organic surfactants on the formation of IOPs in the presence of DOM.

The addition of HA to the system (NA + NaI) led to a particle increase from $8 \cdot 10^{3}$ to $8 \cdot 10^{5} \# / \mathrm{cc}$, which is explained by the reactions to the surfactant air/water interface and the photosensitizer. The same behavior is recorded in the presence of SA as the surfactant. These results show that the presence of an organic surfactant in the medium reduces the yield of organoiodine formation $\mathrm{OIC}_{S}$ which increases the concentration of IOP.

\section{Conclusions}

In this work, the formation of iodine particles in the presence of ubiquitous surfactants at the air/sea interface was studied for the first time. We found that the number of IOP decreased in the presence of surfactants (NA, SA) and dissolved organic matter. This behavior was explained by the formations of OIC. A strong production of IOP was observed during the irradiation of the reactor in the absence of DOM and the surfactants, whereas the release of IOP in the presence of these organic compounds remained rather moderate. The PTR-ToF-MS data gas phase SA shows that there is no formation of VOCs, which explains the difference between the results obtained using SA and NA. It should be noted that up to now, the mechanisms of production of IOP has been studied taking into account only the processes directly related to the photochemistry of marine salts as iodine. However, the presence of organic compounds at bulk or at the interface strongly affects the process, since iodine is captured by the latter. On the other hand, the results obtained by the photochemistry of surfactants (NA, SA) which lead to the emission of VOCs in the atmosphere, shows that the number of SOA is very low $(200 \# / c c)$ under these conditions. The increase in the concentration of ozone (e.g. $800 \mathrm{ppb}$ ) leads to a strong increase of SOA, for that we have to work with the atmospheric conditions, by simulating the photochemical reactions that can take place in the atmosphere.

\section{Acknowledgements}

This study was supported by the European Research Council under the Horizon 2020 Research and Innovation Program Project of the European Union under Convention $\mathrm{N}^{\circ} 690958$ (MARSU). The authors thank University Claude Bernard for the technical and financial support provided by the Institute for Research on Catalysis and the Environment of Lyon (IRCELYON).

We thank Mr. Christian George who participated during all the stages of preparation of this paper except the redaction. 


\section{References}

[1] Shinichi E., Michael R.: J. Phys. Chem. A., 2016, 120, 3578. http://doi.org/10.1021/acs.jpca.6b01261

[2] Simpson W., Brown S., Saiz-Lopez A. et al.: Chem. Rev., 2015, 115, 4035. https://doi.org/10.1021/cr5006638

[3] Sbai S., Farida B.: Environ. Sci. Pollut. Res., 2019, 1. https://doi.org/10.1007/s11356-019-05012-5

[4] Sakamoto Y., Yabushita A., Kawasaki M., Enami S.: J. Phys. Chem., 2009, 113, 7707. https://doi.org/10.1021/jp903486u

[5] Hayase S., Yabushita A., Kawasaki M. et al.: J. Phys. Chem., 2010, 114, 6016. https://doi.org/10.1021/jp101985f

[6] Sayaka H., Akihiro Y., Masahiro K.: J. Phys. Chem. A, 2012, 116, 5779. https://pubs.acs.org/doi/abs/10.1021/jp2048234.

[7] Saiz-Lopez A., Plane J.: Geophys. Res. Lett., 2004, 31, L04112. https://doi.org/10.1029/2003GL019215

[8] Read K., Mahajan A., Carpenter L. et al:: Nature, 2008, 453, 1232. https://doi.org/10.1038/nature07035

[9] Saiz-Lopez A., Chance K., Liu X. et al.: Geophys. Res. Lett., 2007, 34, L12812. https://doi.org//10.1029/.2007GL030111

[10] Saiz-Lopez A., Shillito J., Coe H., Plane J.: Atmos. Chem. Phys., 2006, 6, 1513. https://doi.org/10.5194/acp-6-1513-2006

[11] Saiz-Lopez A., Mahajan A., Salmon R. et al.: Science, 2007, 317, 348. https://doi.org/10.1126/science. 1141408

[12] Baker A.: Environ. Chem., 2005, 2, 295.

https://doi.org/10.1071/EN05070

[13] Gilfedde B., Lai S., Petri M. et al.: Atmos. Chem. Phys., 2008, 20, 6069. https://doi.org/10.5194/acp-8-6069-2008

[14] Baker A.: Environ. Chem., 2005, 2, 295.

https://doi.org/10.1071/EN05070

[15] Russell W., Saunders R., Samantha M., John M.: Environ. Sci.

Technol., 2012, 46, 11854. https://doi.org/10.1021/es3030935

[16] Saunders R., Plane J.: Environ. Chem., 2005, 2, 299.

https://doi.org/10.1071/EN05079

[17] Saunders R., Kumar R., Martin J. et al.: Phys. Chem., 2010, 224

,1095. https://doi.org/10.1524/zpch.2010.6143

[18] Pechtl S., Schmitz G., Von Glasow R.: Atmos. Chem. Phys.,

2007, 7, 1381. https://doi.org/10.5194/acp-7-1381-2007

[19] Mahajan A., Plane J., Oetjen H. et al.: Atmos. Chem. Phys. 2010, 10, 4611. https://doi.org/10.5194/acp-10-4611-2010

[20] Read K.: Nature, 2008, 453, 1232.

https://doi.org/10.1038/nature07035

[21] Jones C.: Geophys. Res. Lett., 2010, 37, L18804.

https://doi.org/10.1029/2010GL043990

[22] Carpenter L.: Chem. Rev., 2003, 103, 4953.

https://doi.org/10.1021/cr0206465

[23] Reeser D., Donaldson D.: Atmos. Environ., 2011, 45, 6116.

https://doi.org/10.1016/j.atmosenv.2011.08.042

[24] Frew N.: J. Geophys. Res., 2004, 109, C08S17.

https://doi.org/10.1029/2003JC002131

[25] Garabetian F., Romano J., Paul R., Sigoillot J.: Mar. Environ. Res., 1993, 35, 323. https://doi.org/10.1016/0141-1136(93)90100-E [26] Schneider J., Gagosian R.: J. Geophys. Res., 1985, 90, 7889. https://doi.org/10.1029/JD090iD05p07889

[27] Facchini M., Rinaldi M., Decesari S. et al.: Geophys. Res. Lett., 2008, 35, L17801. https://doi.org/10.1029/2008GL034250

[28] Kovac N., Bajt O., Faganeli J. et al.: Mar. Chem., 2002, 78, 205. https://doi.org/10.1016/S0304-4203(02)00033-6

[29] Tervahattu H., Juhanoja J., Vaida V. et al.: J. Geophys. Res., 2005, 110, D6. https://doi.org/10.1029/2004JD005400

[30] Tervahattu H., Juhanoja J., Kupiainen K.: J. Geophys. Res., 2002, 107, D16. https://doi.org/10.1029/2001JD001403
[31] Tervahattu H., Hartonen K., Kerminen V. et al.: J. Geophys. Res., 2002, 107, D7. https://doi.org/10.1029/2000JD000282

[32] Wurl O., Wurl E., Miller L. et al.: Biogeosciences, 2011, 8, 121. https://doi.org/10.5194/bg-8-121-2011

[33] Bernard R., Ciuraru A., George C.: Environ. Sci. Technol., 2016, 50, 8678. https://doi.org10.1021/acs.est.6b03520

[34] Zhinen H., Yongguang Y., Dong C., Jing-fu L.: Environ.

Sci.Technol., 2017, 51, 5464. https://doi.org/10.1021/acs.est.6b03887 35] Gallard H., Allard S., Nicolau R. et al.: Environ. Sci. Technol., 2009, 43, 7003. https://doi.org/10.1021/es9010338

[36] Leri A., Hakala J., Marcus M. et al.: Biogeochem., 2010, 24, GB4017. https://doi.org/10.1029/2010GB003794

[37] Komaki Y., Pals J., Wagner E. et al.: Environ. Sci. Technol., 2009, 43, 8437. https://doi.org/10.1021/es901852z

[38] Wang L., Zhou X., Fredimoses M. et al.: RSC Adv., 2014, 422, 57350. https://doi.org/10.1039/C4RA09833A

[39] Leri A., Ravel B.: Environ. Sci.Technol., 2015, 49, 13350.

https://doi.org/10.1021/acs.est.5b03937

[40] Ciuraru R., Fine L., Van Pinxteren M. et al.: Sci. Rep., 2015, 5, 12741. https://doi.org/10.1038/srep12741

[41] Ciuraru R., Fine L., Van Pinxteren M. et al.: Environ. Sci. Technol., 2015, 49, 13199. https://doi.org/10.1021/acs.est.5b02388

[42] Peter A., Ciuraru R., Stéphanie R. et al.: Sci. Rep.,2017, 7,12693. https://doi.org/10.1038/s41598-017-12601-2

[43] Wang L., Zhou X., Fredimoses M. et al.: RSC Adv., 2014, 101, 57350. https://doi.org/10.1039/C4RA10456K

[44] Gallard H., Allard S., Nicolau R. et al.: Environ. Sci. Technol., 2009, 43, 7003. https://doi.org/10.1021/es9010338

[45] Leri A., Ravel B.: Environ. Sci. Technol., 2015, 49, 13350. https://doi.org/10.1021/acs.est.5b03937

[46] Marchisio A., Minella M., Maurino V. et al.: Water Res., 2015, 73, 145. https://doi.org/10.1016/j.watres.2015.01.016

[47] Laurentiis E., Minella M., Maurino V. et al.: Sci. Total. Environ., 2012, 439, 299. https://doi.org/10.1016/j.scitotenv.2012.09.037 [48] Saunders R., Kumar R., MacDonald S., Plane J.: Environ. Sci. Technol., 2012, 46, 11854. https://doi.org/10.1021/es3030935

[49] Zhang P., Sun D., Wen M. et al.: Adv. Synth. Catal., 2012, 354, 720. https://doi.org/10.1002/adsc.201290006

[50] Heeb M., Criquet J., Zimmermann-Steffens S., von Gunten U.: Water Res., 2014, 48, 15. https://doi.org/10.1016/j.watres.2013.08.030

Received: February 26, 2018 / Revised: March 21, 2018 / Accepted: August 23, 2018

\section{ДОСЛІДЖЕННЯ ЧАСТИНОК ОКСИДУ ЙОДУ НА ПОВЕРХНІ РОЗДІЛУ ФАЗ ПОВІТРЯ/ВОДА У ПРИСУТНОСТІ ПОВЕРХНЕВО-АКТИВНИХ РЕЧОВИН ТА ГУМІНОВОЇ КИСЛОТИ}

Анотація. У присутності поверхнево-активних речовин (нонанової НК та стеаринової СК кислот) та гумінової кислоти (ГК) досліджено формування частинки оксиду йоду (ОЙЧ). Встановлено, щчо оксид йоду, який змішували з органічними сполуками (НК, СК, ГК), а потім опромінювали ксеноновою лампою, приводить до утворення ОЙЧ. Виділення утворених частинок визначалось за допомогою скануючого класифікатора рухомості частинок. Показано, що кількість часток суттево зменшується в присутності НК, СК, ГК; така поведінка пояснюється утворенням йодоорганічних сполук.

Ключові слова: фотохімія, поверхнево-активні речовини, йод, частинка, йодоорганічний. 